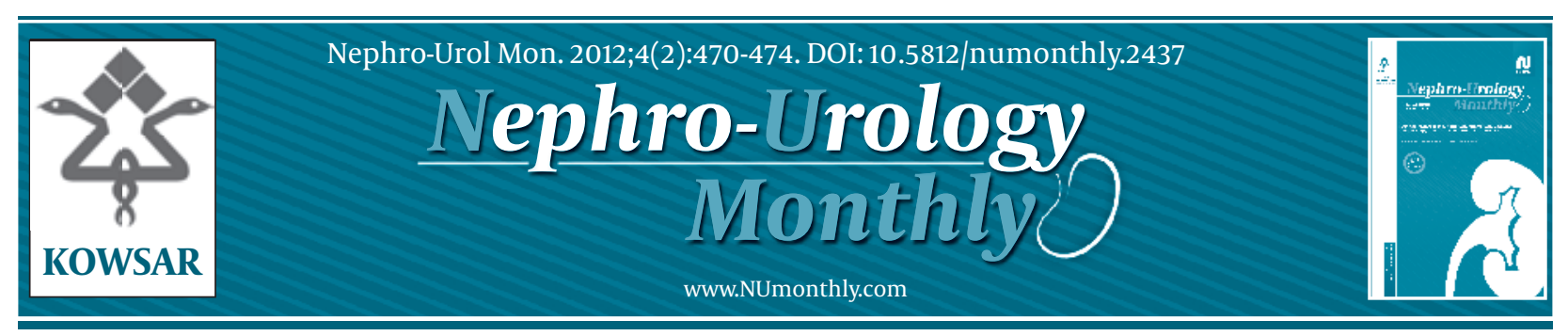

\title{
Change of Cyclosporine Absorption Over the Time After Kidney Trans- plantation
}

\author{
Behzad Einollahi ${ }^{1}$, Mojtaba Teimoori ${ }^{1}$, Zohreh Rostami ${ }^{*}$ \\ ${ }^{1}$ Nephrology and Urology Research Center, Baqiyatallah University of Medical Sciences, Tehran, IR Iran
}

\begin{tabular}{l}
\hline A R T I C L E I N F O \\
\hline Article type: \\
Original Article \\
\hline Article history: \\
Received: 27 Sep 2011 \\
Revised: 06 Oct 2011 \\
Accepted: 17 Oct 2011 \\
\hline
\end{tabular}

Keywords:

Cyclosporine

Delayed Graft Function

Kidney Transplantation

\begin{abstract}
A B S T R A C T
Background: Although the immunosuppressant cyclosporine (CsA) is widely used after kidney transplantation over the long term, there is still no firm consensus on the best way to monitor of CsA blood levels.

Objectives: Cyclosporine (CsA) assay is critical for the management of renal transplant recipients due to inter- and intra-patient variation in CsA absorption and metabolism. Patients and Methods: In a retrospective cross sectional study, blood levels of CsA(through and 2 hours post dose) measured at least 5 times during 3 years post transplantation, in 7702 kidney transplant recipients from different transplant center of Tehran, IR Iran between 2008 and 2012. Cyclosporine absorption (CA) calculated C2/C0 ratio.

Results: CA had a significant correlation with allograft function $(P=0.000, \mathrm{r}=.0 .285)$, this correlation was stronger than its relationship with $\mathrm{C} 0$ and $\mathrm{C} 2$ blood levels $(P=0.000$ and $P=0.000$ as well as $r=0.033$ and $r=0.090$, respectively). In univariate analysis during different times after transplantation, $\mathrm{CO}$ and $\mathrm{C} 2$ blood levels significantly decreased over three years follow up $(P=0.000),(P=0.000)$; While, CA reversely increases over the time $(P=0.000)$. In linear regression model overall CA levels had correlation with lower age of recipient $(P=0.02)$, hypokalemia $(P=0.001)$, higher level of creatinine $(P=0.02)$ and triglyceride $(P=0.001)$.

Conclusions: The present study shows that CsA absorption changes trough the post-transplant time and appears to increases over time in long-term period after kidney transplantation.

Copyright $\odot 2012$ Kowsar M. P. Co. All rights reserved.
\end{abstract}

Implication for health policy/practice/research/medical education:

This article focuses on $\mathrm{C} 2 / \mathrm{CO}$ ratio and it's contributing factors over the time.

- Please cite this paper as:

Einollahi B, Teimoori M, Rostami Z. Change of Cyclosporine Absorbtion Over the Time After Kidney Transplantation. Nephro-Urol Mon.2012;4(2): 470-4. DOI:10.5812/numonthly.2437

\section{Background}

Although the immunosuppressant cyclosporine (CsA) is widely used after kidney transplantation over the long term, there is still no firm consensus on the best way to monitor CsA blood levels (1). It is routinely monitored by predosage blood trough level (CO) or two hours post dose level (C2). In fact, these measurements cannot certainly assess the individual biological impact of the CsA.

* Corresponding author: Zahra Rostami, Nephrology and Urology Research Center, Baqiyatallah University of Medical Sciences, Tehran, IR Iran. Tel/Fax: +98-81262073, E-mail: rostami@numonthly.com

DOI:10.5812/numonthly.2437

Copyright $\odot 2012$ Kowsar M. P. Co. All rights reserved.
Optimization of CsA effect on recipient's immune system is critical to increase short- and long-term outcomes in kidney transplants. Despite improvement in therapeutic CsA monitoring, allograft rejection and CsA nephrotoxicity are still two important problems in kidney transplant patients (2).

There is a day-to-day variability of CsA absorption (CA), described as $\mathrm{C} 2 / \mathrm{CO}$ (3) ratio, and inter-individual variability in drug level is highest within the absorption phase ( 0 to $4 \mathrm{~h}$ post-dose) and satisfactory CsA blood concentration in this period is important for its efficacy (4). Thus, the CsA level assays are critical for the management of renal transplant recipients due to inter- and intra-patient variations in CsA absorption and metabolism. Moreover, 
some researchers have suggested that a combination of $\mathrm{CO}$ and C2 blood level assays may be a beneficial method for evaluating the CsA absorption profile, because it involves both the elimination and the absorption phases (Co and C2) (5-6). The CsA absorption (C2/CO ratio) is also practical for determining the high or low CsA absorbers $(5,6)$. The limited published data are available in literature in terms of CsA absorption profiling over time in renal transplant patients (5-9).

\section{Objectives}

To our knowledge, these studies are limited by relatively small sample sizes and short-term follow up. In a series of 98 kidney transplants, the absorption profile of CsA is evaluated during the first year after transplantation (5). Therefore, we conducted a retrospective study to assess the CsA absorption, as described by $\mathrm{C} 2 / \mathrm{CO}$ ratio, during the first three post-transplant years in a large renal transplant population.

\section{Patients and Methods}

\subsection{Study Population}

In a retrospective cross sectional study, blood levels of CsA measured in 7702 kidney transplant recipients from different transplant center of Tehran, I.R. Iran between 2008 and 2012 were analyzed. All measurements were performed in a single laboratory. Ethical approval of research was confirmed by the Local Ethics Committee of University.

\subsection{Immunosuppressant}

Immunosuppressance was based on CsA plus mycophenolate mofetil or azathioprine and prednisolone in all patients . In most centers, CsA doses given to kidney recipients were administered mostly upon CsA trough levels. CsA measurement was assessed at different times and dose was adjusted as local protocol and in case of necessity. Our therapeutic target ranges for Co levels were 200 to $300 \mathrm{ng} / \mathrm{mL}$ in 1 to 3 months, 100 to $250 \mathrm{ng} / \mathrm{mL}$ in 4 to 12 months and 100 to $150 \mathrm{ng} / \mathrm{mL}$ in more than 1 year after transplantation; while C2 target levels were 800 to $1000 \mathrm{ng} / \mathrm{mL}$ in months one to three after transplantation and C2 targets of 400 to $600 \mathrm{ng} / \mathrm{mL}$ for subsequent months.

\subsection{Laboratory Data Collection}

Routine laboratory investigations included creatinine
(Cr), uric acid, hemoglobin ( $\mathrm{Hb})$, sodium, potassium, phosphorous, cholesterol (Chol), triglyceride (TG), high density lipoprotein cholesterol (HDL), low density lipoprotein cholesterol (LDL). Blood was collected in the morning after a 12-hour fasting period. The biochemical assays were performed by the same laboratory using automatic systems with various relevant methods including enzymatic method (blood urea nitrogen, Chol, TG, HDL, LDL), modification of the kinetic Jaffe reaction (Cr). All methods for biochemical assays had inter- and intraassay coefficients of variation within 5\%. CsA levels were determined from whole blood using the Cobas Mira-Plus analyzer (Roche). Cyclosporine absorption (CA) was calculated by $\mathrm{C} 2 / \mathrm{CO}$ ratio.

\subsection{Statistical Analysis}

The SPSS version 17.0 for Windows was used in all the analysis. Quantitative variables were expressed as mean \pm standard deviation (SD), while qualitative variables were shown by number and percentage. The kolmogorovsimirnov test showed that C0, C2 and calculated CA was not distributed normally; hence, Spearman's correlation analysis was used to study correlations between CA, CO and $\mathrm{C} 2$ concentrations with numeric variable such as serum $\mathrm{Cr}$, age of recipient, TG, LDL, HDL and $\mathrm{Hb}$. We used a formula Ln (CA) to normalize the CA distribution for linear regression model. Linear logistic regression, backward model was used for analyze factors with the greatest explanatory effect on CA level. ANOVA model used to evaluate a change in 5 different times of $\mathrm{CO}, \mathrm{C} 2$ and $\mathrm{CA}$ level during 3 years of follow up. We also used generalized linear model (GLM) for detecting effect of categorical variable such type of donor and gender of donor and recipient on $\mathrm{C} 0, \mathrm{C} 2$ and $\mathrm{CA}$. A $P<0.05$ was regarded as a significant level and 95\% confidence interval was also considered to be a reliable estimate. We used $P<0.2$ for entering variable in to linear regression model.

\section{Results}

\subsection{Demographical Setting}

A total of 7702 patients were recruited from different Transplant Centers of Iran. The mean age of recipients was $37 \pm 15$ years (range: 3 to 83 years); 63\% male and $37 \%$ female (Table 1). The mean age of donors was $28 \pm 6$ years (range: 5 to 62 years); $83 \%$ male and $17 \%$ female. The majority of grafts came from living donors (84\% unrelated and $8 \%$ related), whereas $8 \%$ of patients received a deceased donor graft.

\begin{tabular}{|c|c|c|c|c|c|c|}
\hline & 0-3, mo & 4 to $6, \mathrm{mo}$ & 7-12, mo & 2nd, y & 3rd, y & PValue \\
\hline $\begin{array}{l}\text { Cyclosporine } \\
\text { trough level }\end{array}$ & $254.85 \pm 116.16$ & $197.60 \pm 88.25$ & $168.09 \pm 78.02$ & $153.29 \pm 80.21$ & $145.49 \pm 87.25$ & 0.000 \\
\hline $\begin{array}{l}\text { Cyclosporine } 2 \\
\text { hours post dose }\end{array}$ & $764.90 \pm 162.93$ & $636.15 \pm 127.67$ & $575.89 \pm 115.80$ & $539.48 \pm 152.75$ & $500.55 \pm 180.15$ & 0.000 \\
\hline $\begin{array}{l}\text { Cyclosporine } \\
\text { absorption }\end{array}$ & $3.38 \pm 0.83$ & $3.82 \pm 0.90$ & $4.05 \pm 1.07$ & $4.22 \pm 1.10$ & $4.33 \pm 1.24$ & 0.000 \\
\hline
\end{tabular}


Table 2. Relation of Baseline Characteristics of Patients With Cyclosporine $\mathrm{A}$

\begin{tabular}{lll}
\hline & Sig.(2-tailed) & Spearman's Correlation \\
\hline Age of recipient & 0.000 & -0.142 \\
$\mathrm{Hb}^{\mathrm{a}}$ & 0.004 & -0.092 \\
$\mathrm{HDL}^{\mathrm{a}}$ cholesterol & 0.153 & -0.054 \\
LDL $^{\text {a }}$ cholesterol & 0.039 & -0.080 \\
Triglycerides & 0.000 & -0.165 \\
potassium & 0.002 & -0.083 \\
phosphorus & 0.000 & 0.099 \\
Sodium & 0.004 & 0.077 \\
Creatinine & 0.000 & 0.132 \\
Blood urea & 0.103 & -0.040 \\
\hline abbreviations:Hb,Hemoglobin; HDL, high density lipoprotein; LDL, low den- \\
sity lipoprotein
\end{tabular}

Table 3. Overall CA Levels and Correlation With Other Variable in Linear Regression Model

\begin{tabular}{|c|c|c|c|}
\hline Time & Pvalue & $\beta$ & S.E ${ }^{\mathrm{a}}$ \\
\hline \multicolumn{4}{|l|}{ First three months } \\
\hline $\mathrm{Cr}^{\mathrm{a}}$ & 0.02 & 0.177 & 0.114 \\
\hline \multicolumn{4}{|l|}{ Second year } \\
\hline Age of recipient & 0.02 & -0.005 & 0.002 \\
\hline $\mathrm{TG}^{\mathrm{a}}$ & 0.001 & 0.003 & 0.001 \\
\hline \multicolumn{4}{|l|}{ Third year } \\
\hline Age of recipient & 0.000 & -0.003 & 0.001 \\
\hline K & 0.001 & -0.091 & 0.029 \\
\hline
\end{tabular}

a Abbreviations: SE, standard error; Cr, Creatinine, TG, Triglgceride

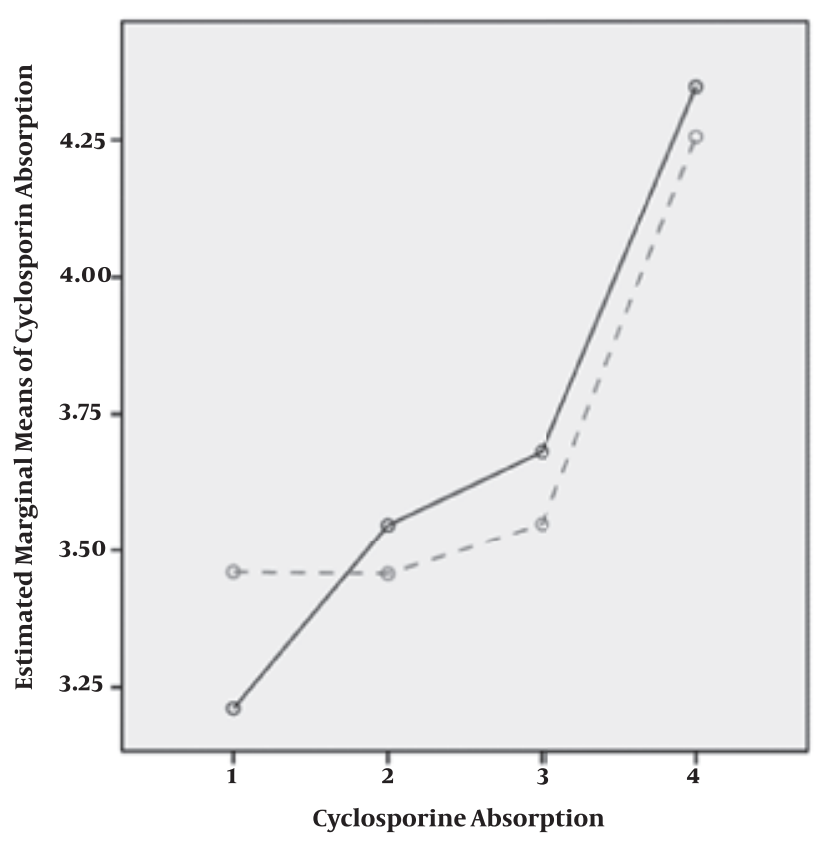

Figure 1. Cyclosporine Absorbtion Change Among Men and Female Throughout a Four Time Patient Follow up.

\subsection{Correlation of CA and Allograft Function}

CA had a significant correlation with allograft function $(P=0.000, \mathrm{r}=0.285)$, this correlation was stronger than its relationship with C0 and C2 blood levels $(P=0.000$ and 0.000 as well as $r=0.033$ and 0.090 , respectively).

\subsection{Univariate Analysis}

In five different times after transplantation, $\mathrm{Co}$ and $\mathrm{C} 2$ blood levels significantly decreased over three years follow up; while, CA reversely increased over the time (Table 1). We found that lower age of recipient, hypokalemia, hypernatremia, hypotriglyceridemia, anemia, higher $\mathrm{Cr}$ concentration and lower LDL were significantly related to CA (Table 2).

\subsection{Generalized Linear Model}

In our patients, measurement of $\mathrm{CO}$ and $\mathrm{C} 2$ and CA levels was repeated after changing dose in four periods post transplantation. All patients were long-term transplant patients with decrease in $\mathrm{C} 0$ and $\mathrm{C} 2$ and increase in CA. Coefficient of variation for more than four repeated measurements with dose change was 57.1\% (C0), 65.4\% (C2) and $128 \%$ (C2/C0). CA trend was increasing through time $(P=0.00)$. Co correlation level was different among males and females $(P=0.00)$ but $C 2$ and CA were has not different trend in both genders $(P=0.27)$ in male and $(P=$ 0.83) in female (Figure 1).

\subsection{Linear Regression Model}

Overall CA levels had correlation with lower age of recipient, hypokalemia, higher level of $\mathrm{Cr}$ and TG concentrations (Table 3).

\section{Discussion}

The present study shows that CsA absorption changes through the post-transplant time and appears to increase over time in long-term period after kidney transplantation. Buchler et al. reported that although CsA dose and levels decreased between months 3 and 12, an increase in the ratio of $\mathrm{C} 2$ to $\mathrm{C} 0$ was seen within this period of renal transplantation (5). Optimized drug level early after transplantation is still a problem for a significant proportion of kidney transplant recipients (10). Although it shows that absorption of CsA is highly heterogeneous immediately post-transplant period, it increases early after kidney transplantation allowing a reduction in CsA dose to achieve constant exposure $(5,7)$. Furthermore, we found that CsA levels significantly decrease over first three post-transplant years. Buchler et al. have also shown that $\mathrm{CO}$ and $\mathrm{C} 2$ blood levels decreased between months 3 and 12 after kidney transplantation (5). In an international study, CsA doses were decreased over the time while the absorptions of drug were increased (11). Most of studies show that CsA dose reduction is safe in long-term transplant patients $(2,12,13)$, and this may be because of improvement in drug absorption. However, a 
wide alteration in drug absorption is seen among renal transplant recipients due to variable pharmacokinetics of CsA. Effect of concomitant medication and foods are also important (3).

It is clear that greater initial CsA doses to achieve the therapeutic concentrations immediately after transplantation is required to prevent acute rejection (10). In addition, this requirement to higher initial doses of drug may be partly due to the low initial CsA absorption and the low relative bioavailability early after transplantation. Felipe et al reported a significant increasing timedependent in steady state of CsA exposure occurred within the first month of kidney transplantation (14). It has been reported that a high intra-individual variability of Co concentrations is associated with a greater incidence of acute and chronic rejection episodes, reduced 5-year graft survival and increased serum creatinine (15). The CsA absorption phase is important for inhibition of T-cell that is maximally achieved when there is an adequate amount of CsA exposure in the early post-dose period (3). The amount of T-cell inhibition relate to the concentration of existing CsA to enter the T cells (3). Variations in CsA absorption have a key role in avoiding overuse of CsA which is prone to nephrotoxicity (3). Although the CsA absorption increases during the early phase after surgery, it may be mainly related to drug accumulation after several dose administrations, and the further CA increases is observed afterward it is most likely correlated to time-dependent changes in relative CA. Interestingly, increase in CA was seen among our patients during three post-transplant years, it means that an increase in drug absorption occurred over the time. This also suggests that the initial higher doses of CsA day would be sufficient to produce therapeutic concentrations for only immediate phase after transplantation. In fact, the relative bioavailability CsA increases over time $(16,17)$.

The CA of oral CsA administration is usually decreased after transplant surgery, that is parallel to the type and length of anesthesia, hydration, and decreased intestinal motility (18). This increased trend may be attributed to a progressive increase in CA from small intestine and/ or a progressive enhance in CsA metabolism. In a study which revealed that CYP3A4 and PGP activity decreases over time post-transplant (19). The window of CA in the gastrointestinal tract, and differences in content and activity of CYP3A4 and P-glycoprotein may still significantly have control on the absorption of CsA from the microemulsion formulation (20-23). Consequently, higher CsA doses early after transplantation are necessary if beneficial concentrations are to be aimed.

The mechanisms involved in this effect are not fully implicated yet $(17,24)$. In rats, blood CsA absorption get higher after daily administration and are associated with a reduction in hepatic $\mathrm{P} 450$ protein expression and microsomal metabolic activity, which suggests that timedependent P450 suppression by CsA may explain, at least in part, the experiential time-dependent variations in CsA pharmacokinetics $(23,25,26)$.

We found no gender difference among CsA absorption; which resembles with the previous finding (27). Roza et al. showed that awareness of the concerns that some patients might absorb CsA differently than others (28), potential differences between gender, ethnicity, and the presence of diabetes were not seen. They demonstrated that male and female kidney transplant recipients responded in the same manner (27). In addition, we found that age may significantly effect CA. Although some studies have shown that age of donor and recipient both are risk factors for acute and chronic rejection episode (29, 30)(31-32), other studies reported that in this group of patients, CsA level tend to be lower (31). However, Sugiyama et al. (32) demonstrated that pharmacodynamic parameters of immunosuppressive drugs did not correlate with age of renal transplant recipients (33). An experimental study on rabbits showed that renal impairment has an important effect on CsA blood levels (34). On the other hand, some other studies showed that CsA dose have linear relation to serum creatinine concentration $(27,33)$. It is assumed that the decrease in creatinine clearance can result in accumulation of CsA, especially in C2 level, and therefore CA increases during time (35).

Some studies revealed that both CsA nephropathy and hypokalemia may result in renal injuries by chronic vasoconstriction and in combination (36), which is confirmed by our finding. The effect of triglycerides on CA was our another finding of this study, CsA leads to rise in serum LDL and serum free fatty acid level because of insulin resistance and also reduce number and function of hepatic LDL receptors; thus, it seems that CsA and especially higher level of CA may result in accumulation of triglycerides (37-39).

We conclude that it's better to establish a new marker of CA with regards to absorption profile to avoid any nephrotoxicity because of CsA. Investigation showed that neither CO nor C2 levels seem to be associated with clinical events, and C2 levels seemed to better reflect inter-individual absorption differences. They may help to identify those patients at risk of over-immunosuppression due to good CA absorption and may enable the CA dose to be lowered in those individuals (3). To our knowledge, an increase observed in the $\mathrm{C} 2$ to Co blood levels ratio during 3 years after renal transplantation, which indicate improvement of CA over time, have not been reported elsewhere. We also conclude that $\mathrm{C} 2 / \mathrm{C} 0$ ratio can be useful to select optimal CsA doses in both the early and late post-transplant periods.

\section{Acknowledgments}

There is no acknowledgment.

\section{Financial Disclosure}

There is no financial disclosures. 


\section{Funding/Support}

This study was funded by the Nephrology and Urology Research Center, Baqiyatallah University of Medical Sciences.

\section{References}

1. Rostami Z, Einollahi B. Cyclosporine monitoring in organ transplantation: Do we need a new concept? Nephro-Urol Mon. 2012;3(2):97-8.

2. Tha-In T, Hesselink DA, Tilanus HW, Elshove L, Wilschut AL, Hansen BE, et al. Clinical outcome after cyclosporine dose reduction based on C2 levels in long-term liver transplant patients. Clin Transplant. 2005;19(4):537-42.

3. Einecke G, Mai I, Fritsche L, Slowinski T, Waiser J, Neumayer HH, et al. The value of $\mathrm{C} 2$ monitoring in stable renal allograft recipients on maintenance immunosuppression. Nephrol Dial Transplant. 2004;19(1):215-22.

4. Nashan B, Cole E, Levy G, Thervet E. Clinical validation studies of Neoral C(2) monitoring: a review. Transplantation. 2002;73(9 Suppl):S3-11.

5. Buchler M, Chadban S, Cole E, Midtvedt K, Thervet E, Prestele H, et al. Evolution of the absorption profile of cyclosporine A in renal transplant recipients: a longitudinal study of the de novo and maintenance phases. Nephrol Dial Transplant. 2006;21(1):197-202.

6. Einecke G, Mai I, Diekmann F, Fritsche L, Neumayer HH, Budde K. Cyclosporine absorption profiling and therapeutic drug monitoring using $\mathrm{C}(2)$ blood levels in stable renal allograft recipients. Transplant Proc. 2002;34(5):1738-9.

7. Absorption profiling of cyclosporine microemulsion (neoral) during the first 2 weeks after renal transplantation. Transplantation. 2001;72(6):1024-32.

8. Belitsky P, Dunn S, Johnston A, Levy G. Impact of absorption profiling on efficacy and safety of cyclosporin therapy in transplant recipients. Clin Pharmacokinet. 2000;39(2):117-25.

9. Cyclosporine microemulsion (Neoral) absorption profiling and sparse-sample predictors during the first 3 months after renal transplantation. Am J Transplant. 2002;2(2):148-56.

10. Mahalati K, Belitsky P, West K, Kiberd B, Fraser A, Sketris I, et al. Approaching the therapeutic window for cyclosporine in kidney transplantation: a prospective study. J Am Soc Nephrol. 2001;12(4):828-33.

11. Randomized, international study of cyclosporine microemulsion absorption profiling in renal transplantation with basiliximab immunoprophylaxis. Am J Transplant. 2002;2(2):157-66.

12. Sumethkul V, Tankee P, Chalermsanyakorn P, Jirasiritham S. Long-term outcome of very early cyclosporine minimization and de novo everolimus therapy in kidney transplant recipients: a pharmacokinetic guided approach. Transplant Proc. 2010;42(10):4040-2.

13. Etienne I, Toupance O, Benichou J, Thierry A, Al Najjar A, Hurault de Ligny B, et al. A 50\% reduction in cyclosporine exposure in stable renal transplant recipients: renal function benefits. Nephrol Dial Transplant. 2010;25(9):3096-106.

14. Felipe CR, Silva HT, Jr., Machado PG, Garcia R, Moreira SR, Pestana JO. Time-dependent changes in cyclosporine exposure: implications for achieving target concentrations. Transpl Int. 2003;16(7):494-503.

15. Waiser J, Slowinski T, Brinker-Paschke A, Budde K, Schreiber M, Bohler T, et al. Impact of the variability of cyclosporin A trough levels on long-term renal allograft function. Nephrol Dial Transplant. 2002;17(7):1310-7.

16. Grevel J, Post BK, Kahan BD. Michaelis-Menten kinetics determine cyclosporine steady-state concentrations: a population analysis in kidney transplant patients. Clin Pharmacol Ther. 1993:53(6):651-60.

17. Awni WM, Kasiske BL, Heim-Duthoy K, Rao KV. Long-term cyclosporine pharmacokinetic changes in renal transplant recipients: effects of binding and metabolism. Clin Pharmacol Ther. 1989;45(1):41-8.

18. Gubbins PO, Bertch KE. Drug absorption in gastrointestinal disease and surgery. Clinical pharmacokinetic and therapeutic implications. Clin Pharmacokinet. 1991;21(6):431-47.

19. Lemahieu WP, Maes BD, Verbeke K, Vanrenterghem YF. Alterations of CYP3A4 and P-glycoprotein activity in vivo with time in renal graft recipients. Kidney Int. 2004;66(1):433-40.

20. Hebert MF. Contributions of hepatic and intestinal metabolism and P-glycoprotein to cyclosporine and tacrolimus oral drug delivery. Adv Drug Deliv Rev. 1997;27(2-3):201-14.

21. Lampen A, Christians U, Bader A, Hackbarth I, Sewing KF. Drug interactions and interindividual variability of ciclosporin metabolism in the small intestine. Pharmacology. 1996;52(3):159-68.

22. Lown KS, Mayo RR, Leichtman AB, Hsiao HL, Turgeon DK, Schmiedlin-Ren P, et al. Role of intestinal P-glycoprotein (mdr1) in interpatient variation in the oral bioavailability of cyclosporine. Clin Pharmacol Ther. 1997;62(3):248-60.

23. Brunner LJ, Bennett WM, Koop DR. Cyclosporine suppresses rat hepatic cytochrome P450 in a time-dependent manner. Kidney Int. 1998;54(1):216-23.

24. Amante AJ, Meier-Kriesche HU, Schoenberg L, Kahan BD. A pharmacokinetic comparison of the corn oil versus microemulsion gelcap formulation of cyclosporin used de novo after renal transplantation. Transpl Int. 1997;10(3):217-22.

25. Barone G, Chang CT, Choc MG, Jr., Klein JB, Marsh CL, Meligeni $\mathrm{JA}$, et al. The pharmacokinetics of a microemulsion formulation of cyclosporine in primary renal allograft recipients. The Neoral Study Group. Transplantation. 1996;61(6):875-80.

26. Kovarik JM, Mueller EA, Richard F, Niese D, Halloran PF, Jeffery J, et al. Evidence for earlier stabilization of cyclosporine pharmacokinetics in de novo renal transplant patients receiving a microemulsion formulation. Transplantation. 1996;62(6):759-63.

27. Cole E, Maham N, Cardella C, Cattran D, Fenton S, Hamel J, et al. Clinical benefits of neoral C2 monitoring in the long-term management of renal transplant recipients. Transplantation. 2003;75(12):2086-90.

28. Curtis JJ, Lynn M, Jones PA. Neoral conversion from Sandimmune in maintenance renal transplant patients: an individualized approach. J Am Soc Nephrol. 1998;9(7):1293-300.

29. Khalkhali HR, Ghafari A, Hajizadeh E, Kazemnejad A. Risk factors of long-term graft loss in renal transplant recipients with chronic allograft dysfunction. Exp Clin Transplant. 2010;8(4):277-82.

30. Cheung CY, Chan HW, Chan YH, Chau KF, Li CS. Impact of delayed graft function on renal function and graft survival in deceased kidney transplantation. Hong Kong Med J. 2010;16(5):378-82.

31. Ekberg H, Tedesco-Silva H, Demirbas A, Vitko S, Nashan B, Gurkan A, et al. Reduced exposure to calcineurin inhibitors in renal transplantation. N Engl J Med. 2007;357(25):2562-75.

32. Sugiyama K, Isogai K, Toyama A, Satoh H, Saito K, Nakagawa Y, et al. Pharmacodynamic parameters of immunosuppressive drugs are not correlated with age, duration of dialysis, percentage of lymphocytes or lymphocyte stimulation index in renal transplant recipients. Biol Pharm Bull. 2008;31(11):2146.

33. Midtvedt K, Fauchald P, Bergan S, Hoieggen A, Hallan S, Svarstad E, et al. C2 monitoring in maintenance renal transplant recipients: is it worthwhile? Transplantation. 2003;76(8):1236-8.

34. Karim MS, Wood RF, Dawnay AB, Fulton PA. The effect of renal ischemia on cyclosporine clearance in rabbits. Transplantation. 1990;49(3):500-2.

35. Moyer TP, Johnson P, Faynor SM, Sterioff S. Cyclosporine: a review of drug monitoring problems and presentation of a simple, accurate liquid chromatographic procedure that solves these problems. Clin Biochem. 1986;19(2):83-9.

36. Nakagawa T, Kang DH, Ohashi R, Suga S, Herrera-Acosta J, Rodriguez-Iturbe $\mathrm{B}$, et al. Tubulointerstitial disease: role of ischemia and microvascular disease. Curr Opin Nephrol Hypertens. 2003;12(3):233-41.

37. Massy ZA, Kasiske BL. Post-transplant hyperlipidemia: mechanisms and management. J Am Soc Nephrol. 1996;7(7):971-7.

38. Princen HM, Meijer P, Wolthers BG, Vonk RJ, Kuipers F. Cyclosporin A blocks bile acid synthesis in cultured hepatocytes by specific inhibition of chenodeoxycholic acid synthesis. Biochem J.1991;275 ( Pt 2):501-5.

39. Markell MS, Armenti V, Danovitch G, Sumrani N. Hyperlipidemia and glucose intolerance in the post-renal transplant patient. $J$ Am Soc Nephrol. 1994;4(8 Suppl):S37-47. 